\title{
Thoracic range of motion, stability, and correlation to imaging-determined degeneration
}

\author{
Andrew T. Healy, MD, ${ }^{1,2}$ Prasath Mageswaran, PhD, ${ }^{2}$ Daniel Lubelski, BA, ${ }^{3}$ \\ Benjamin P. Rosenbaum, MD, ${ }^{1}$ Virgilio Matheus, MD, ${ }^{4}$ Edward C. Benzel, MD, ${ }^{1,2}$ and \\ Thomas E. Mroz, MD1,2
}

\begin{abstract}
1Department of Neurological Surgery and ${ }^{2} \mathrm{Head}$ and Neck Research Lab, Cleveland Clinic; ${ }^{3}$ Case Western Reserve University Lerner College of Medicine, Cleveland, Ohio; and ${ }^{4}$ Department of Neurological Surgery, Southeastern Regional Medical Center, Lumberton, North Carolina
\end{abstract}

\begin{abstract}
OBJECT The degenerative process of the spinal column results in instability followed by a progressive loss of segmental motion. Segmental degeneration is associated with intervertebral disc and facet changes, which can be quantified. Correlating this degeneration with clinical segmental motion has not been investigated in the thoracic spine. The authors sought to determine if imaging-determined degeneration would correlate with native range of motion (ROM) or the change in ROM after decompressive procedures, potentially guiding clinical decision making in the setting of spine trauma or following decompressive procedures in the thoracic spine.
\end{abstract}

METHODS Multidirectional flexibility tests with image analysis were performed on thoracic cadaveric spines with intact rib cage. Specimens consisted of 19 fresh frozen human cadaveric spines, spanning C-7 to L-1. ROM was obtained for each specimen in axial rotation (AR), flexion-extension (FE), and lateral bending (LB) in the intact state and following laminectomy, unilateral facetectomy, and unilateral costotransversectomy performed at either T4-5 (in 9 specimens) or T8-9 (in 10 specimens). Image grading of segmental degeneration was performed utilizing 3D CT reconstructions. Imaging scores were obtained for disc space degeneration, which quantified osteophytes, narrowing, and endplate sclerosis, all contributing to the Lane disc summary score. Facet degeneration was quantified using the Weishaupt facet summary score, which included the scoring of facet osteophytes, narrowing, hypertrophy, subchondral erosions, and cysts.

RESULTS The native ROM of specimens from T-1 to T-12 $(n=19)$ negatively correlated with age in AR (Pearson's $r$ coefficient $=-0.42, p=0.070)$ and FE $(r=-0.42, p=0.076)$. When regional ROM (across 4 adjacent segments) was considered, the presence of disc osteophytes negatively correlated with $F E(r=-0.69, p=0.012), L B(r=-0.82, p=$ $0.001)$, and disc narrowing trended toward significance in $A R(r=-0.49, p=0.107)$. Facet characteristics, scored using multiple variables, showed minimal correlation to native ROM ( $r$ range from -0.45 to +0.19$)$; however, facet degeneration scores at the surgical level revealed strong negative correlations with regional thoracic stability following decompressive procedures in AR and LB (Weishaupt facet summary score: $r=-0.52$ and $r=-0.71 ; p=0.084$ and $p=0.010$, respectively). Disc degeneration was not correlated (Lane disc summary score: $r=-0.06, p=0.861$ ).

CONCLUSIONS Advanced age was the most important determinant of decreasing native thoracic ROM, whereas imaging characteristics (T1-12) did not correlate with the native ROM of thoracic specimens with intact rib cages. Advanced facet degeneration at the surgical level did correlate to specimen stability following decompressive procedures, and is likely indicative of the terminal stages of segmental degeneration.

http://thejns.org/doi/abs/10.3171/2014.12.SPINE131112

KEY WORDS spinal degeneration; spinal instability; biomechanics; degenerative; thoracic

\footnotetext{
ABBREVIATIONS AR = axial rotation; Avg\%Change = average percent change following decompressive procedures; $\mathrm{BMD}=$ bone mineral density; $\mathrm{FE}=$ flexion-extension; $\mathrm{LB}=$ lateral bending; $\mathrm{ROM}=$ range of motion.

SUBMITTED April 2, 2014. ACCEPTED December 10, 2014.

INCLUDE WHEN CITING Published online May 15, 2015; DOI: 10.3171/2014.12.SPINE131112.

DISCLOSURE This study was supported in part by funds received through the Cleveland Clinic Stanley Zielony Spinal Research \& Education Fund, the Neurosurgery Research and Education Foundation (NREF), and the Cleveland Clinic Research Programs Committee. The authors report no conflicts of interest concerning the materials or methods used in this study or the findings specified in this paper.
} 
$\mathrm{T}$ HE degenerative process of the spinal column conveys a degree of altered segmental motion until a point at which spinal segments become rigidly fused in a process of "stabilization." Kinetic imaging studies have shown altered motion of facet joints ${ }^{13}$ and spinal segments ${ }^{15}$ associated with degeneration of the intervertebral disc. Resultant altered kinematics likely correlate to signs of degeneration on MRI and CT. Numerous studies have attempted to quantify imaging findings to correlate degeneration to pathological segmental motion in the lumbar and cervical spine. ${ }^{8}$ Of the more than 40 grading systems described in a review by Kettler and Wilke, few used CT imaging, demonstrated acceptable interrater reliability, or showed correlation with biomechanical motion. $3,6,8,11,13,16,19,22$

Fluoroscopic studies have found a correlation between decreasing thoracolumbar range of motion (ROM) and age older than 30 years.,14,17 Biomechanical studies have found that facet joint osteoarthritis is associated with anterior translational instability in the sagittal plane ${ }^{4}$ and that degenerative disc disease initially conveys altered coupled motion in the facet joints. ${ }^{13}$ This subclinical alteration of motion is likely represented by osteophyte formation and spondylosis, quantifiable on static imaging. . $, 6,8,11,13,16,19,22$ Over time, in a bimodal pattern of stability, high-grade degeneration eventually stabilizes a segment, until stabilization is reached.${ }^{16}$ The ability to quantify early pathological motion and distinguish a mobile segment from one undergoing stabilization could perhaps help surgeons identify levels at risk for adjacent-segment degeneration and contribute to surgical planning.

Thus, we sought to determine if existing lumbar degenerative disease grading systems would correlate with native $\mathrm{ROM}$ or the change in ROM after decompressive procedures in the thoracic spine. We hypothesized that systematically graded degenerative changes on CT imaging would correlate with decreased specimen ROM before and after surgical procedures, and that one could use this grading system to predict postsurgical instability and perhaps identify levels at risk for adjacent-segment degeneration.

\section{Methods \\ Specimens}

Specimens consisted of 19 fresh frozen human cadaveric spines spanning C-7 to L-1. Each specimen included the sternum and ribs, with all articulations intact. CT imaging of each specimen was carried out to determine preexisting spinal pathology or fusion. Specimens with previous spinal surgery, spinal implants, soft-tissue abnormalities, or fractures were excluded. Specimens with kyphosis $\left(>65^{\circ}\right)$ or severe scoliosis $\left(>40^{\circ}\right)$ were also excluded. The mean specimen age was 60 years (range $43-70$ years). There were 11 female and 8 male specimens. Each specimen's documented comorbid diagnoses, cause of death, and bone mineral density (BMD) can be found in Table 1 .

Prior to testing, the specimens were removed from a $-20^{\circ} \mathrm{C}$ freezer and thawed, and the surrounding musculature was meticulously dissected, leaving all ligamentous and articular attachments preserved. Custom-designed spinal fixtures were used to secure the spine cranially and caudally onto a robotic spine testing system (KUKA, $\mathrm{GmbH})$. The cranial (C7-T1) and caudal (T12-L1) levels were mounted onto the custom test fixtures using pedicle screws and rods. The test setup was further secured using wood screws inserted into the cranial and caudal vertebral bodies and embedded in Cerrobend, a liquid metal alloy (HiTech Alloys).

\section{Multidirectional Biomechanical Testing}

An industrial robot capable of motion in 6 axes was used as the testing apparatus for implementing in vitro multidirectional flexibility tests. It was used to apply pure moments on the spinal segments through custom-designed mounting fixtures. Multidirectional testing was carried out in 3 orthogonal directions. The 3 test directions corresponded to flexion-extension (FE), lateral bending (LB), and axial rotation (AR) of the thoracic spine. The specimens were unconstrained to allow for natural coupled motion of the spine.

A 6-axis, force-moment sensor (Gamma, ATI) was used to measure the applied load and provide feedback for the robot. The sensor also measured the off-axis forces and moments to provide feedback to ensure that a pure moment was being applied along the primary axis of motion of the spine. 3D motion was monitored continuously using an optoelectronic camera system (Optotrak Certus, Northern Digital Inc.) at a rate of $20 \mathrm{~Hz}$. The camera system measured the vertebral motion by tracking the relative motion between infrared markers rigidly affixed to the vertebral segments. The Optotrak system has a measurement accuracy of $\pm 0.1 \mathrm{~mm}$ in translation and $\pm 0.1^{\circ}$ in rotation. Motion markers were attached to the spinous processes of T-1 and T-12 for all specimens. This "global ROM" measurement was obtained in all 19 specimens.

After testing of the first 7 specimens was complete, minimal changes in overall specimen motion were observed, and it was felt that the addition of optoelectronic sensors placed 2 vertebrae above and below the surgical segment would better capture regional motion changes across the surgical level following decompression. This "regional ROM" measurement was obtained in the final 12 specimens. Posttest analyses were used to determine ROM between segments termed "global" when referring to T1-12 motion $(\mathrm{n}=19)$ and "regional" when referring to motion across the experimental surgical levels $(n=12)$.

On the day of testing, the spine was adjusted to a neutral posture and recorded by the test system and returned to this posture between tests. Nondestructive flexibility testing was then performed on each specimen. The specimens were preconditioned to minimize any viscoelastic effects by being subjected to 3 cycles of FE, LB, and AR at an applied pure moment of $\pm 5 \mathrm{Nm}$ while continuously minimizing all other off-axis loads. The mounted spine was kept moist during testing by periodically spraying exposed tissues with saline solution.

\section{Test Conditions}

Flexibility tests were conducted on each intact specimen, and then repeated again after each sequential surgi- 
TABLE 1. Demographic data for the 19 specimens

\begin{tabular}{|c|c|c|c|c|c|c|c|c|}
\hline $\begin{array}{l}\text { Specimen } \\
\text { No. }\end{array}$ & Age (yrs) & $\begin{array}{l}\text { Height } \\
\text { (ft., in) }\end{array}$ & $\begin{array}{l}\text { Weight } \\
\text { (lbs) }\end{array}$ & Sex & Smoker & Cause of Death & Conditions & $\begin{array}{l}\text { Average Bone Density } \\
\left(\mathrm{g} / \mathrm{cm}^{2}\right)\end{array}$ \\
\hline 1 & 69 & $59^{\prime \prime}$ & 192 & M & Yes & Cardiac arrest & HTN, CVA & 0.145 \\
\hline 2 & 67 & $5^{\prime \prime \prime}$ & 190 & M & Yes & Ml & HTN, CAD & 1.019 \\
\hline 3 & 55 & $6{ }^{\prime \prime \prime}$ & 150 & M & Yes & Cirrhosis & CKD, CVA, IVDA & 1.100 \\
\hline 4 & 65 & $5^{\prime} 5^{\prime \prime}$ & 150 & $\mathrm{~F}$ & Yes & Alzheimer's & OA, CVA, CAD, COPD, DM & 0.979 \\
\hline 5 & 51 & $5^{\prime} 7^{\prime \prime}$ & 220 & $\mathrm{~F}$ & Yes & DM & CHF, pericarditis, CVA, ESRD, OA & 0.962 \\
\hline 6 & 63 & $55^{\prime \prime}$ & 111 & $\mathrm{~F}$ & No & Cholangiocarcinoma & Sepsis, perforated viscus & 0.862 \\
\hline 7 & 52 & $52^{\prime \prime}$ & 143 & $\mathrm{~F}$ & Yes & COPD & CHF, SVT, DM, RA, OA & 1.059 \\
\hline 8 & 45 & $59^{\prime \prime}$ & 119 & $\mathrm{~F}$ & No & Glioblastoma & Seizures, glioblastoma, chemotherapy & 0.920 \\
\hline 9 & 68 & $5 ' 10 "$ & 140 & M & No & Renal failure & Dialysis, MI, DM, OA & 0.789 \\
\hline 10 & 62 & $52^{\prime \prime}$ & 190 & $\mathrm{~F}$ & Yes & Cirrhosis & Chemotherapy, asthma, jaundice & 0.707 \\
\hline 11 & 43 & $5 ' 10 "$ & 250 & $\mathrm{~F}$ & No & Atherosclerosis & HTN & 0.723 \\
\hline 12 & 68 & $54^{\prime \prime}$ & 114 & M & Yes & COPD & PNA, CAD, MI, GIB & 0.777 \\
\hline 13 & 69 & $58^{\prime \prime}$ & 138 & M & Yes & Brain damage & CVA, seizure & 1.083 \\
\hline 14 & 57 & $58^{\prime \prime}$ & 127 & $\mathrm{~F}$ & Yes & $\mathrm{CHF}$ & COPD, PNA, chronic bronchitis & 0.852 \\
\hline 15 & 70 & $5^{\prime} 0^{\prime \prime}$ & 111 & $\mathrm{~F}$ & Yes & COPD & Hypokalemia & 0.642 \\
\hline 16 & 69 & $54^{\prime \prime}$ & 160 & $\mathrm{~F}$ & Yes & Kidney disease & Anemia, HTN & 1.150 \\
\hline 17 & 56 & $5 ' 2 "$ & 167 & $\mathrm{~F}$ & Yes & Stroke & Hemorrhagic CVA & 0.787 \\
\hline 18 & 55 & $5 ' 11 "$ & - & M & Yes & Natural causes & $\mathrm{OA}$ & 0.603 \\
\hline 19 & 59 & $61^{\prime \prime \prime}$ & 190 & M & Yes & NA & HTN & 0.930 \\
\hline
\end{tabular}

$\mathrm{CAD}=$ coronary artery disease $\mathrm{CHF}=$ congestive heart failure $\mathrm{CKD}=$ chronic kidney disease $; \mathrm{COPD}=$ chronic obstructive pulmonary disease; $\mathrm{CVA}=\mathrm{cerebrovascular}$ accident; $D M=$ diabetes mellitus; $E S R D=$ end-stage renal disease; $\mathrm{GIB}=$ gastrointestinal bleed; $\mathrm{HTN}=$ hypertension; IVDA = intravenous drug abuse; $\mathrm{MI}=$ myocardial infarction; NA = not available; OA = osteoarthritis; PNA = pneumonia; RA = rheumatoid arthritis; SVT = supraventricular tachycardia; $-=$ not recorded at time of death.

cal decompressive procedure performed at either T4-5 (n = 9) or T8-9 $(\mathrm{n}=10)$. The sequence of surgical procedures on each specimen was as follows: 1) laminectomy; 2) unilateral facetectomy; and 3) unilateral costotransversectomy. A fellowship-trained spine surgeon and a neurosurgical resident (T.E.M. and A.T.H.) performed the surgical procedures. The operative procedures consisted of removal of only necessary osseous structures while preserving adjacent ligamentous and structural integrity. Laminectomies were performed at either T4-5 or at T8-9 for access to the associated pedicle and interspace. Facetectomy was performed on the right side and involved complete resection of the cranial inferior articular process and the caudal superior articular process of the operative segment. Costotransversectomy included removal of the transverse process, pedicle, and approximately $3 \mathrm{~cm}$ of rib including its articulations with the vertebral column.

\section{CT Image Grading}

Image grading of segmental degeneration was performed on CT images utilizing $3 \mathrm{D}$ reconstructions by a staff neurosurgeon (V.M.) and 2 neurosurgical residents (A.T.H. and B.P.R.). Previously published historical grading systems were used. ${ }^{11,22}$ Lane et al. developed a system utilizing lateral radiographs, ${ }^{11}$ which we adapted for the thoracic spine (Fig. 1). This system included lower thoracic intervertebral levels and was found to have high interrater reliability. Furthermore, this grading system scored osteophytes, sclerosis, and disc height, as did other grading schemes. ${ }^{16,20}$ Each level was scored from 0 to 3 as depicted in Fig. 1 for osteophytes and narrowing. Sclerosis was defined as either present or absent. Each level was then given a summary score (0-2) as described by Lane et al. ${ }^{11}$ Facet grading was performed as described by Weishaupt et al. (Table 2) 22 and adapted for the thoracic spine (Fig. 2). Originally described for MRI ${ }^{19}$ this system was subsequently found to correlate well with CT imaging, ${ }^{22}$ was tested for interrater reliability, ${ }^{8}$ and was shown to correlate with lumbar motion in cadaveric ${ }^{5}$ and kinetic MRI studies. ${ }^{10}$

\section{Data Analysis}

Global (T1-12) and regional (either T3-7 or T7-11) ROMs were obtained for each specimen at peak moment $(5 \mathrm{Nm})$ in the 3 primary planes of motion for each test condition. Each specimen thus acted as its own control. The 19 specimens were tested in the intact state and following the surgical procedures described above. Statistical analysis was performed using Minitab 16 (Minitab Inc.). Pearson $r$ coefficient of linear correlation was determined for each of the following scoring variables: disc narrowing, disc osteophytes, endplate sclerosis, disc summary score ${ }^{11}$ facet narrowing, facet osteophytes, facet erosions, subchondral cysts, and facet summary score..$^{22}$ Statistical significance was determined with a confidence interval of $95 \%$. To compare the imaging scores to the motion of their respective segments, each specimen's mean imaging scores were: 1) summated across all thoracic levels, 2) summated across regional levels only, and 3) scored at the surgical level only. 


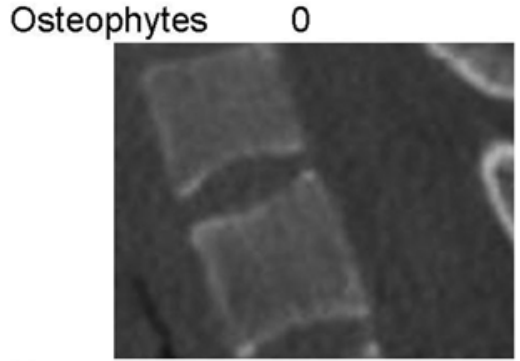

Narrowing 0

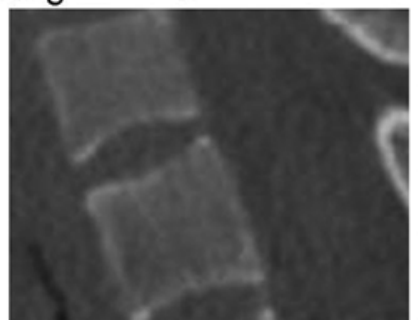

1

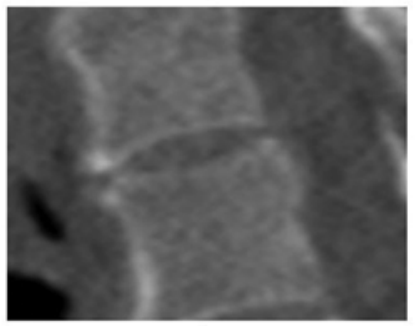

1

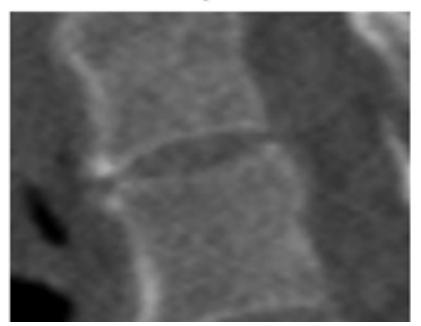

2

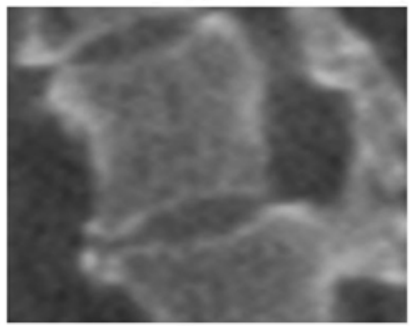

2

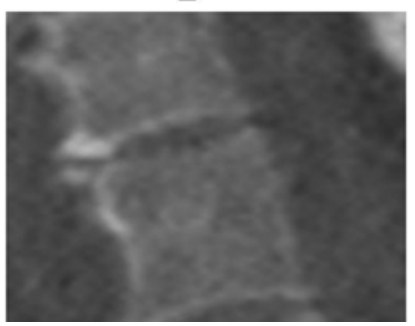

3

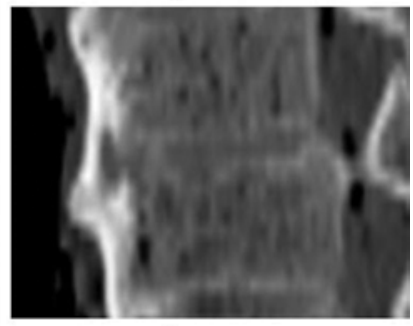

3

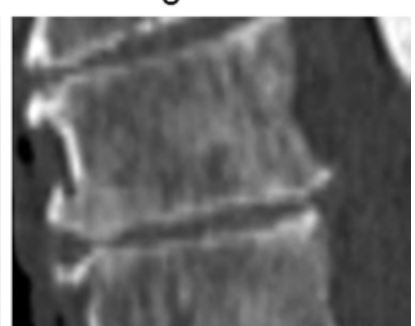

FIG. 1. Intervertebral disc grading system adapted from Lane et al. and adjusted for the thoracic spine. Lane score "0" for normal intervertebral disc, "1" for mild degeneration, "2" for moderate, and "3" for severe.

\section{Results}

\section{Age and Segmental Degeneration}

Increasing age demonstrated significant correlation to imaging-determined segmental degeneration in the thoracic spine. Facet hypertrophy $(r=0.46, p=0.045)$, disc narrowing $(r=0.48, p=0.034)$, disc osteophytes $(r=0.53$, $\mathrm{p}=0.018)$, and the disc summary score $(\mathrm{r}=0.59, \mathrm{p}=0.007)$ were all found to exhibit strong correlation to increasing age (Table 3).

\section{Age, Degeneration, and Native Specimen ROM}

When comparing the global ROM to the independent variables in question, we found that only age correlated to native specimen ROM, trending toward significance with negative correlation in AR $(\mathrm{r}=-0.42, \mathrm{p}=0.070), \mathrm{FE}(\mathrm{r}=$ $-0.42, p=0.076)$, and LB $(r=-0.34, p=0.154)$. BMD did not correlate with the intact global ROM. Imaging criteria did not correlate with native specimen ROM when scores were summated across all thoracic segments. When the

\section{TABLE 2. Reiteration of the facet grading system*}

\begin{tabular}{ccccc}
\hline & \multicolumn{4}{c}{ Facet Characteristics } \\
\cline { 2 - 5 } Grade & Joint Space & Osteophytes & Hypertrophy & $\begin{array}{c}\text { Articular } \\
\text { Surface }\end{array}$ \\
\hline 0 & Normal $(2-4 \mathrm{~mm})$ & None & None & Normal \\
\hline 1 & Narrow $(<2 \mathrm{~mm})$ & Small & Mild & Normal \\
\hline 2 & Narrow $(<2 \mathrm{~mm})$ & Moderate & Moderate & $\begin{array}{c}\text { Early subar- } \\
\text { ticular ero- } \\
\end{array}$ \\
& & & & sions \\
\hline 3 & "Severe" & Large & Severe & $\begin{array}{c}\text { Subarticular } \\
\text { erosions \& } \\
\end{array}$ \\
& & & & $\begin{array}{c}\text { subchon- } \\
\text { dral cysts }\end{array}$ \\
\hline
\end{tabular}

\footnotetext{
* As described by Weishaupt et al. and originally by Pathria et al.
}

regional segments were scored and analyzed, the presence of disc osteophytes demonstrated negative correlation to ROM in FE $(r=-0.69, p=0.012)$ and LB $(r=-0.82, p=$ $0.001)$. Disc narrowing demonstrated a trend toward significant negative correlation in AR $(r=-0.49, \mathrm{p}=0.107)$. The facet summary score and facet characteristics did not correlate with native ROM, with $r$ values for facet characteristics ranging from -0.24 to +0.19 .

\section{Thoracic ROM Following Decompression}

When the imaging scores from T-1 through T-12 were summated and compared with global average percent change following the decompressive procedures (Avg\%Change), few variables were found to correlate ( $\mathrm{r}$ value range -0.37 to +0.09 ). Age did not significantly correlate with Avg\%Change. When considering the imaging scores of the surgical levels (T4-5 or T8-9), we found significant correlations between CT-determined degeneration and the Avg\%Change in regional ROM following decompressive procedures (Table 4). Avg\%Change in AR following decompression trended toward significant negative correlation with all facet attributes: narrowing $(\mathrm{r}$ $=-0.44, \mathrm{p}=0.149)$, osteophytes $(\mathrm{r}=-0.50, \mathrm{p}=0.095)$, hypertrophy $(\mathrm{r}=-0.45, \mathrm{p}=0.143)$, erosions $(\mathrm{r}=-0.48$, $\mathrm{p}=0.118)$, and the facet summary score $(\mathrm{r}=-0.52, \mathrm{p}=$ $0.084)$. The strongest correlations were found in LB. Facet degeneration negatively correlated with $\mathrm{Avg} \%$ Change in ROM following decompression: narrowing $(\mathrm{r}=-0.89$, $\mathrm{p}<$ $0.001)$, osteophytes $(r=-0.71, p<0.001)$, hypertrophy $(r=$ $-0.62, p=0.033)$, erosions $(r=-0.68, p=0.015)$, and the facet summary score $(r=-0.71, p=0.010)$, whereas disc degeneration demonstrated no statistical correlation (disc summary score $r=-0.06, p=0.861$ ).

\section{Discussion}

ROM of a single spinal segment is affected by multiple factors. Age has been previously described, with de- 

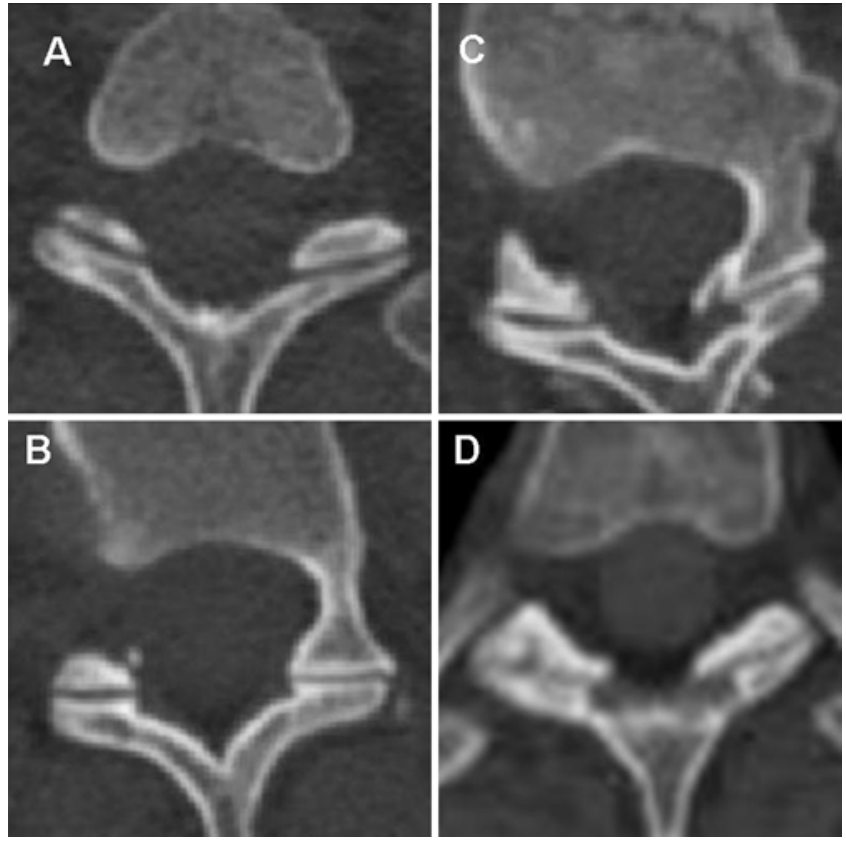

FIG. 2. Facet grading system adapted from Weishaupt et al. and adjusted for the thoracic spine. Facets were graded in a similar fashion. A: Normal facet characteristics. B: Mild degeneration with small osteophytes and mild narrowing. C: Moderate degeneration with areas of joint space obliteration, possible erosion, and moderate osteophytes. D: Severe degeneration with subchondral cyst formation, large osteophytes, and joint space obliteration.

creasing lumbar ROM after 34 years of age. ${ }^{17}$ Disc height, osteophyte formation, and facet degeneration have also been suggested to correlate with segmental motion abnormalities in both lumbar imaging and biomechanical studies. ${ }^{4,10,16}$ However, a quantifiable way to measure the extent of degeneration based on imaging that can correlate with
TABLE 4. Correlation between imaging scores, age, and ROM following surgical decompression at either T4-5 or T8-9*

\begin{tabular}{|c|c|c|c|}
\hline \multirow[b]{2}{*}{ Variable } & \multicolumn{3}{|c|}{$\begin{array}{c}\text { Avg\%Change in Postprocedural } \\
\text { Regional Thoracic ROM } †\end{array}$} \\
\hline & $A R$ & FE & LB \\
\hline Age & 0.36 & -0.51 & 0.01 \\
\hline BMD & -0.46 & 0.17 & -0.25 \\
\hline \multicolumn{4}{|l|}{ Facets } \\
\hline Narrowing & -0.44 & -0.28 & $-0.89 \ddagger$ \\
\hline Osteophytes & -0.50 & -0.20 & $-0.71 \ddagger$ \\
\hline Hypertrophy & -0.45 & 0.13 & $-0.62 \ddagger$ \\
\hline Erosions & -0.48 & -0.14 & $-0.68 \ddagger$ \\
\hline \multicolumn{4}{|l|}{ Subchondral cysts } \\
\hline Facet summary score & -0.52 & -0.02 & $-0.70 \ddagger$ \\
\hline \multicolumn{4}{|l|}{ Discs } \\
\hline Narrowing & 0.24 & -0.23 & 0.01 \\
\hline Osteophytes & 0.06 & -0.19 & 0.24 \\
\hline Sclerosis & 0.40 & $-0.6377 \ddagger$ & 0.32 \\
\hline Disc summary score & 0.04 & -0.26 & -0.06 \\
\hline \multicolumn{4}{|c|}{$\begin{array}{l}\text { * Values represent Pearson } r \text { values. Values in boldface indicate } p<0.1 \text { or } \ddagger p \\
<0.05 \text {. The percent change after laminectomy, facetectomy, and costotrans- } \\
\text { versectomy were averaged to obtain a single value, representing motion } \\
\text { following decompressive surgery. } \\
\dagger \text { ROM captured from } 2 \text { vertebrae above and } 2 \text { below the surgical level (being } \\
\text { either T4-5 or T8-9). }\end{array}$} \\
\hline
\end{tabular}

spinal motion has not been defined in the thoracic spine. Along these lines, one could measure this degeneration to quantify subclinical instability or segmental "stabilization." Defining segmental instability prior to the development of apparent motion on dynamic imaging could help the surgeon identify levels at risk for adjacent-segment degeneration and assist in preoperative planning.

TABLE 3. Correlation between imaging scores, age, and ROM in the native state prior to surgical decompression*

\begin{tabular}{|c|c|c|c|c|c|c|c|}
\hline \multirow[b]{2}{*}{ Variable } & \multirow[b]{2}{*}{ Age } & \multicolumn{3}{|c|}{ Native Thoracic Global ROM† } & \multicolumn{3}{|c|}{ Native Thoracic Regional ROM } \\
\hline & & AR & FE & LB & AR & $\mathrm{FE}$ & LB \\
\hline Age & & -0.42 & -0.42 & -0.34 & -0.08 & -0.21 & -0.49 \\
\hline BMD & & 0.19 & 0.15 & 0.19 & -0.59 & -0.38 & -0.33 \\
\hline \multicolumn{8}{|l|}{ Facets } \\
\hline Narrowing & 0.11 & -0.11 & 0.04 & 0.04 & -0.24 & 0.12 & -0.08 \\
\hline Osteophytes & 0.06 & -0.12 & -0.24 & 0.05 & 0.13 & 0.04 & -0.12 \\
\hline Hypertrophy & $0.46 \S$ & -0.24 & -0.08 & 0.01 & -0.06 & 0.13 & -0.05 \\
\hline Erosions & 0.08 & -0.29 & -0.07 & -0.01 & -0.45 & -0.23 & -0.18 \\
\hline Subchondral cysts & 0.21 & -0.25 & 0.09 & 0.08 & -0.28 & 0.03 & -0.04 \\
\hline Facet summary score & 0.19 & -0.24 & 0.03 & -0.03 & -0.19 & 0.19 & 0.01 \\
\hline \multicolumn{8}{|l|}{ Discs } \\
\hline Narrowing & $0.48 \S$ & 0.00 & -0.09 & 0.02 & -0.49 & -0.20 & -0.20 \\
\hline Osteophytes & $0.53 \S$ & -0.17 & -0.44 & -0.16 & -0.37 & $-0.69 \S$ & $-0.82 \pi$ \\
\hline Sclerosis & 0.32 & -0.12 & 0.09 & -0.15 & -0.34 & 0.09 & -0.06 \\
\hline Disc summary score & $0.59 \S$ & -0.04 & -0.18 & 0.01 & -0.31 & -0.15 & -0.28 \\
\hline
\end{tabular}


We hypothesized that degeneration on imaging would clearly correlate to decreasing motion in the native state. We found that this was largely not the case. In fact, in the native state, age was more indicative of decreasing spinal motion, and only certain imaging characteristics were found to correlate. The presence of disc osteophytes did correlate with reduced native motion, only in LB. This finding has been seen in prior studies in which LB was most dramatically reduced with severe disc degeneration. ${ }^{16}$ Other variables previously described in the literature demonstrated no significant correlation to native ROM, including facet joint narrowing, facet osteophytes, facet subchondral erosion and cyst formation, or disc space sclerosis. Previous work in the lumbar spine has repeatedly lent support to the Kirkaldy-Willis process of spinal degeneration. ${ }^{4,9,16}$ However, Nachemson et al. reported that even though severely degenerated levels may have conveyed decreasing flexibility, the degree of interspecimen variability "overshadowed" differences conveyed by age, sex, and segmental degeneration. ${ }^{18}$ More recent work has consistently found that as segmental degeneration increases, there is increased instability until "severe" degeneration is reached., ${ }^{4,10,12,16}$ The specimens in the present study were of older age and only a few exhibited "mild" degeneration; accordingly we did not expect, nor were we able, to detect bimodal stability. The linear correlations we observed are concordant with previous studies: moving from moderate to severe degeneration correlates with decreasing ROM.16

We previously found that cadaveric specimens experienced no significant change in motion following thoracic laminectomy, facetectomy, or even unilateral costotransversectomy, when the ventral spine remained intact. ${ }^{71}$ In our work, the mean ROM was unchanged before and after decompressive procedures; however, there was substantial variability among the specimens. Two of 19 specimens appeared to have significant changes postdecompression, with a $79 \%$ average increase in FE in one specimen (Fig. 3 ) and a $102 \%$ average increase in LB in the another (Fig.
4). Anecdotally, the ages of these "mobile" specimens were 67 and 69 years. Subjectively, both specimens had a moderate amount of degenerative change on CT imaging and variable degrees of ankylosis at each level (Figs. 3 and 4). We therefore sought to determine if the imaging characteristics of thoracic segments could predict postoperative segmental instability (i.e., an increase in postoperative ROM).

This stability following surgical procedures is important and has not been investigated previously. In the present study we found that in AR, Avg\%Change following decompression was negatively correlated with all facet attributes and strongly associated to the Weishaupt facet summary score $(r=-0.52, p=0.084)$ but not to most disc attributes $(r=+0.039$ to +0.397$)$. In FE, we found that Avg\%Change following decompression exhibited strong negative association to disc endplate sclerosis $(\mathrm{r}=-0.64$, $\mathrm{p}=0.026$ ), which may indicate more severe degeneration. The strongest correlations were found in LB. Facet degeneration exhibited strong, negative correlation with Avg\%Change, including the Weishaupt facet summary score $(r=-0.70, p=0.010)$.

Imaging criteria were found to correlate well to change in ROM following surgical procedures but were largely inconsequential in the native state. Perhaps the segmental stability conveyed by severely degenerated levels might be overshadowed by the stability of the rib cage and the small magnitude of difference at the thoracic level in the intact state. These changes are likely more pronounced, or uncovered, following decompression. Similarly, a recent biomechanical study of prognostic factors for stability in lumbar segments found few correlations to imaging prior to laminectomy, but it did find osteophytes and the Weishaupt facet score to correlate with increasing shear stiffness following laminectomy. ${ }^{2}$ In our study, facet degeneration was more indicative of stability following decompression and perhaps more accurately represents the final stages of aberrant segmental motion in the thoracic
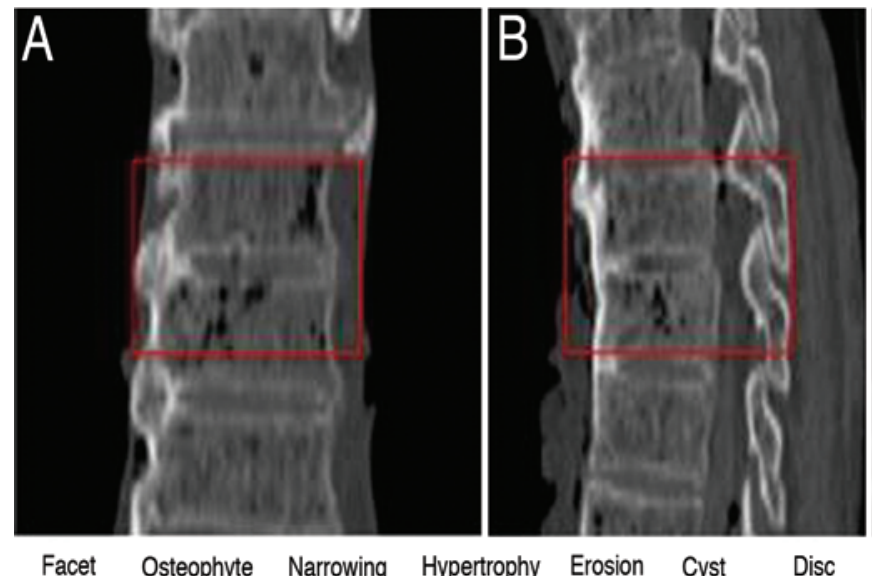

Facet
Summary

0.67

2

0.67

2
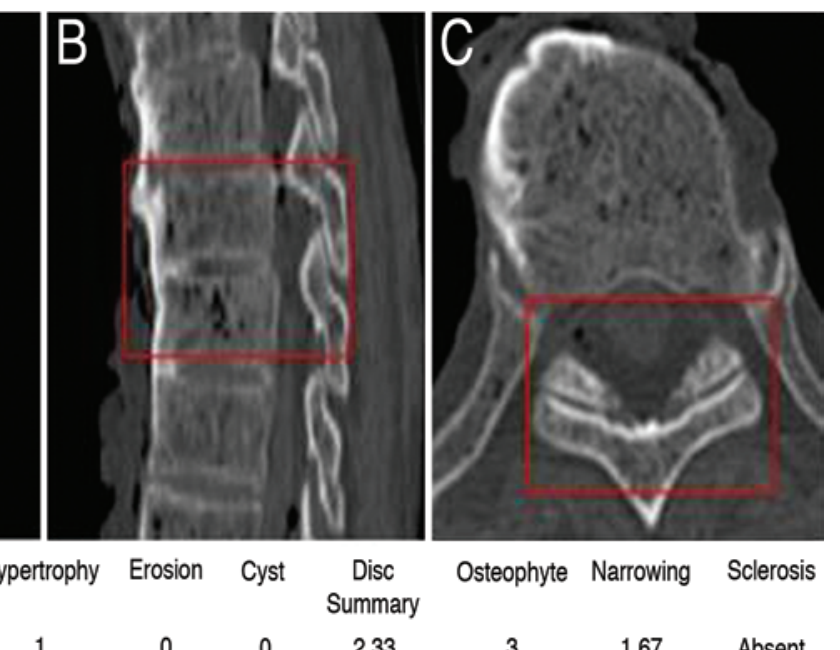

Osteophyte Narrowing Sclerosis

2.33

3

1.67

Absent

FIG. 3. CT images for "mobile" Specimen A. This specimen achieved $14.8 \%$ average increase in AR and $79 \%$ in FE following decompressive procedures. Coronal (A), sagittal (B), and axial (C) images depicting large bridging osteophytes centrally and on the right of the disc space, with moderate disc space narrowing. Facet degeneration is mild to moderate. Average scores from 3 independent reviewers for each variable appear in the table below the images. Figure is available in color online only. 

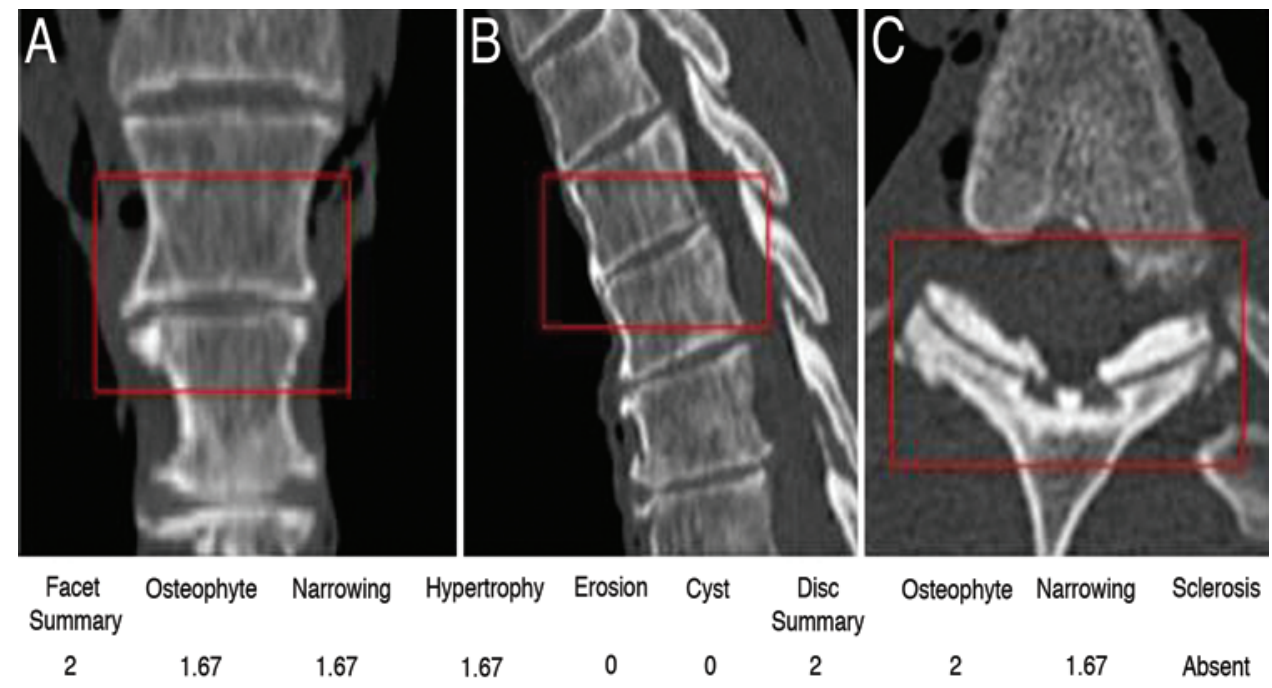

FIG. 4. CT images for "mobile" Specimen B. This specimen achieved $9.6 \%$ average increase in AR, $49 \%$ in FE, and $102 \%$ in LB. Coronal (A), sagittal (B), and axial (C) images depicting a moderate osteophyte midline across the ventral disc space, with moderate disc space narrowing. Facet degeneration is moderate. Average scores from 3 independent reviewers for each variable appear in the table below the images. Figure is available in color online only.

spine. This is similar to previous evidence that radiographic disc degeneration precedes facet changes. ${ }^{4,10}$

Based on our results, it appears that advanced facet degeneration was more indicative of postoperative stability, whereas disc degeneration showed trends toward regional instability. Figures 3 and 4 depict specimens that experienced large increases in segmental motion in the postoperative state. In a clinical situation, large bridging osteophytes, as seen in Fig. 3, may falsely convey stability to the surgeon. Conversely however, we found disc degeneration to be reflective of instability. Severe facet hypertrophy, subchondral erosions, and facet joint narrowing likely mark the later stages of segmental degeneration and, in our study, more reliably indicate postoperative stability. It is possible that facet changes can predict segmental stabilization clinically, and future studies of adjacent-segment pathology or segmental instability should report disc and facet scores to better elucidate the role of CT-based image scoring and its relationship to segmental stability. With the ability to identify the stability of a segment, one could apply such grading to preoperative planning strategies.

\section{Limitations}

In our investigation, we used specimen data from previous studies in which ROM was not measured on a segmental level, but rather on a regional and global basis. Because the rib cage was intact in our specimens, we were unable to place optoelectronic sensors at the levels just above and below the surgical level and had to place them on undisturbed posterior elements an additional level above and below the decompression site. We felt that any clinically relevant instability at the surgical level would at least be detected when measuring motion across 4 levels. Furthermore, our study used specimens with a narrow age range, all of which had moderate to severe degeneration, thus limiting our ability to generalize these findings to patients of all ages. Finally, as with any cadaveric study, differences in tissue handling and preparation may affect the results. To limit this effect, all specimens were consistently prepared by the same investigator (P.M.).

\section{Conclusions}

Advanced age, as opposed to other measures of spinal segmental degeneration, was the most important determinant of native thoracic ROM. Although image grading of segmental degeneration did not correlate with the native ROM, advanced facet degeneration at the surgical level displayed strong correlations to specimen stability postoperatively. Imaging characteristics of an operative level may predict stability to a greater extent than would be appreciated when testing intact spinal columns and should be considered in future investigations of postoperative or posttraumatic spinal stability.

\section{References}

1. Allbrook D: Movements of the lumbar spinal column. J Bone Joint Surg Br 39-B:339-345, 1957

2. Bisschop A, van Royen BJ, Mullender MG, Paul CP, Kingma I, Jiya TU, et al: Which factors prognosticate spinal instability following lumbar laminectomy? Eur Spine J 21:26402648, 2012

3. Demaerel P, Wilms G, Goffin J, Baert AL: Osteoarthritis of the facet joints and its role in low-back pain: evaluation with conventional tomography. J Belge Radiol 75:81-86, 1992

4. Fujiwara A, Tamai K, Yamato M, An HS, Yoshida H, Saotome $\mathrm{K}$, et al: The relationship between facet joint osteoarthritis and disc degeneration of the lumbar spine: an MRI study. Eur Spine J 8:396-401, 1999

5. Grogan J, Nowicki BH, Schmidt TA, Haughton VM: Lumbar facet joint tropism does not accelerate degeneration of the facet joints. AJNR Am J Neuroradiol 18:1325-1329, 1997

6. Gunzburg R, Parkinson R, Moore R, Cantraine F, Hutton $\mathrm{W}$, Vernon-Roberts B, et al: A cadaveric study comparing discography, magnetic resonance imaging, histology, and 
mechanical behavior of the human lumbar disc. Spine (Phila Pa 1976) 17:417-426, 1992

7. Healy AT, Lubelski D, Mageswaran P, Bhowmick DA, Bartsch AJ, Benzel EC, et al: Biomechanical analysis of the upper thoracic spine after decompressive procedures. Spine J 14:1010-1016, 2014

8. Kettler A, Wilke HJ: Review of existing grading systems for cervical or lumbar disc and facet joint degeneration. Eur Spine J 15:705-718, 2006

9. Kirkaldy-Willis WH, Farfan HF: Instability of the lumbar spine. Clin Orthop Relat Res 165:110-123, 1982

10. Kong MH, Morishita Y, He W, Miyazaki M, Zhang H, Wu $\mathrm{G}$, et al: Lumbar segmental mobility according to the grade of the disc, the facet joint, the muscle, and the ligament pathology by using kinetic magnetic resonance imaging. Spine (Phila Pa 1976) 34:2537-2544, 2009

11. Lane NE, Nevitt MC, Genant HK, Hochberg MC: Reliability of new indices of radiographic osteoarthritis of the hand and hip and lumbar disc degeneration. J Rheumatol 20:19111918,1993

12. Lee MJ, Bransford RJ, Bellabarba C, Chapman JR, Cohen AM, Harrington RM, et al: The effect of bilateral laminotomy versus laminectomy on the motion and stiffness of the human lumbar spine: a biomechanical comparison. Spine (Phila Pa 1976) 35:1789-1793, 2010

13. Li W, Wang S, Xia Q, Passias P, Kozanek M, Wood K, et al: Lumbar facet joint motion in patients with degenerative disc disease at affected and adjacent levels: an in vivo biomechanical study. Spine (Phila Pa 1976) 36:E629-E637, 2011

14. Lindahl O: Determination of the sagittal mobility of the lumbar spine. A clinical method. Acta Orthop Scand 37:241254,1966

15. Lubelski D, Healy AT, Mageswaran P, Benzel EC, Mroz TE: Biomechanics of the lower thoracic spine after decompression and fusion: a cadaveric analysis. Spine J 14:2216-2223, 2014

16. Mimura M, Panjabi MM, Oxland TR, Crisco JJ, Yamamoto I, Vasavada A: Disc degeneration affects the multidirec- tional flexibility of the lumbar spine. Spine (Phila Pa 1976) 19:1371-1380, 1994

17. Moll JM, Wright V: Normal range of spinal mobility. An objective clinical study. Ann Rheum Dis 30:381-386, 1971

18. Nachemson AL, Schultz AB, Berkson MH: Mechanical properties of human lumbar spine motion segments. Influence of age, sex, disc level, and degeneration. Spine (Phila Pa 1976) 4:1-8, 1979

19. Pathria M, Sartoris DJ, Resnick D: Osteoarthritis of the facet joints: accuracy of oblique radiographic assessment. Radiology 164:227-230, 1987

20. Pfirrmann CW, Metzdorf A, Zanetti M, Hodler J, Boos N: Magnetic resonance classification of lumbar intervertebral disc degeneration. Spine (Phila Pa 1976) 26:1873-1878, 2001

21. Saraste H, Broström LA, Aparisi T, Axdorph G: Radiographic measurement of the lumbar spine. A clinical and experimental study in man. Spine (Phila Pa 1976) 10:236-241, 1985

22. Weishaupt D, Zanetti M, Boos N, Hodler J: MR imaging and CT in osteoarthritis of the lumbar facet joints. Skeletal Radiol 28:215-219, 1999

\section{Author Contributions}

Conception and design: Mroz, Healy, Mageswaran. Acquisition of data: Healy, Mageswaran, Lubelski, Rosenbaum, Matheus. Analysis and interpretation of data: Healy, Mageswaran, Lubelski, Rosenbaum, Matheus. Drafting the article: Healy, Mageswaran, Lubelski, Rosenbaum, Matheus. Critically revising the article: all authors. Reviewed submitted version of manuscript: all authors. Statistical analysis: Healy, Mageswaran, Lubelski, Matheus. Study supervision: Mroz.

\section{Correspondence}

Thomas E. Mroz, Departments of Orthopaedic and Neurological Surgery, The Cleveland Clinic, 9500 Euclid Ave., S-40, Cleveland, OH 44195. email: mrozt@ccf.org. 